\title{
The Avoidance of Non-finite Verbs for Senior High Students in China
}

\author{
Shanshan Huang ${ }^{1, *}, \dagger$, Kaining $\mathrm{Mo}^{2, \dagger}$, Chen Xie ${ }^{3, \dagger}$, Jialuo Zhang ${ }^{4, \dagger}$ \\ ${ }^{1}$ School of Language and Translation, Macao Polytechnic Institute, Macao, 820004, China \\ ${ }^{2}$ School of Foreign Studies, South China Normal University, Guangzhou, 510631, Guangdong Province, China \\ ${ }^{3}$ School of Business, Griffith University, Queensland, 4215, Australia \\ ${ }^{4}$ School of Central China Normal University, Wuhan, 430079, Hubei province, China \\ ${ }^{*}$ Corresponding author. Email: p1907712@ipm.edu.mo \\ Those authors contributed equally.
}

\begin{abstract}
Avoidance is a significant linguistic phenomenon in the process of second language learning, especially in writing. Writing is an effective form of language output and reflect the students' capability of using grammar. To meet the requirement of writing, high school students are supposed to use non-finite verbs. However, avoidance strategies are used based on observation. This paper mainly tries to offer explanations for students' avoidance behaviors by conducting an empirical study via questionnaire among 114 participants including high school students, people who are non-English majors but pass different kinds of English examinations, students in English majors and some teachers teaching English in high schools. It is found that students avoid the non-finite verb consciously or unconsciously to ensure the correct rate in the important exam such as IELTS. Moreover, the significance and high examination fee prevent students to try to use non-finite structure as it is a kind of unfamiliar although complex grammar structure. However, the number of tests is limited, so trial and error is so costly in writing that they avoid it rather than try and error. In addition, most people would prefer to use compound sentences and clauses to replace using non-finite verb to reduce making grammar mistakes. During the learning process, negative transfer of mother tongue Chinese is also a cause of avoidance. Furthermore, the complex grammar uses of non-finite verb confuse students and therefore they choose not to use it. This paper also gives some advice to teachers on improving the use of non-finite verbs including reducing the first language negative transfer and improving teaching methods and learners' comprehensive ability.
\end{abstract}

Keywords: Avoidance, Non-finite verbs, Senior high students, China.

\section{INTRODUCTION}

As one of the four foundational language skills in English learning, writing plays an important role in high school English teaching, and constantly draws the attention of researchers. Taking up nearly $17 \%$ percent of proportions in the total scores (25 points) of the current College Entrance Examination in China, writing remains the key focus of ongoing studies. With the efforts of most researchers and teachers, significant achievements have been gained. Meanwhile, there are still problems left unsolved. For example, some students have problems in complex sentence structures and vocabulary and prefer to write with a simplified version. These problems draw forth the avoidance phenomenon.
Avoidance phenomenon has been widely studied by scholars all over the world. It has been proved to be worth researching. It was firstly mentioned by American linguist Jacquelyn Schachter in her thesis. An Error in Error Analysis in the year of 1974. In her study, she brought the notion "avoidance" into light. After Schachter, more linguists showed interests in avoidance and pushed this study into a much wider and greater depth. For example, Krashen used monitor hypothesis to explain avoidance, and Faerch and Kasper also showed their concerns in this field and examined it from psychological aspect.

The present thesis studies avoidance phenomenon based on English writing teaching. We choose avoidance in terms of non-finite verbs in high school 
English writing as the research subject due to the following two reasons.

Firstly, as mentioned above, avoidance phenomenon is important among the research of Second Language (L2) teaching theories. This study on avoidance has maintained a constant upward trend within the recent five years, which shows that avoidance is now attracting more and more attentions in China. But at the same time, there are still no Chinese monographs published, that is to say, these efforts are still necessary in this field, and they are worth-making.

Secondly, avoidance as an existing phenomenon and communicative strategy has its own advantages, and in some degree, could trigger backwash effects too. That is to say, avoidance phenomenon shelters L2 learners from difficult language forms, words and expressions in their target language. For instance, compared with attributive clause and other syntax rule, non-finite verbs, as a difficult English grammar, is always avoided consciously or unconsciously by beginners. Besides that, avoidance phenomenon makes the error analysis lose its effectiveness. With students avoid making mistakes, the real problems in their Second Language Acquisition (SLA) will remain to be hidden, and beyond the reach of examinations. Thus this study has its own special importance.

Thus, we decide to approach avoidance in non-finite verbs from the aspect of high school English writing and tries to focus on "why do they avoid" and hopes to find out countermeasures that could provide suggestions for teachers to benefit students' English writing.

\section{REVIEW OF LITERATURES}

According to Elyildirim, avoidance speech is a group of sociolinguistic phenomena, and it is also one of the common strategies employed by second language learners in the creation of the target language when they have inadequate and incomplete knowledge about grammatical rules and lexical items [1]. In the process of using language, learners commonly use the language avoidance principle intentionally or unintentionally when facing some difficult grammar points. In oral English, learners will use simple words to replace or explain the difficult parts they want to express. In writing, they use simple grammar instead of complex grammar.

According to Ahmed, morphological, syntactic, semantic, pragmatic, and semantic-pragmatic avoidance are the five main types of avoidance [2]. When language learners use a second language, they will subconsciously avoid language difficulties, but they do not know which aspect of linguistics they are avoiding. If the learners can understand the specific content that they are avoiding, they can improve their second language level on purpose. Furthermore, teachers can adjust their teaching methods to achieve better learning effects.

Zhou pointed out that some second language learners have applied the avoidance strategy as one of the important learning methods, which has a very negative impact on their language learning [3]. However, the avoidance strategy in some cases is also a performance of second language learners' active use of communication.

Ahmed also stated that language is an effective communicative force and avoidance strategies are used by second language learners to ensure that communication is not broken [2]. In a positive sense, the use of avoidance strategies reflects the active maintenance of communication effectiveness by language learners. From this paper, one of the significances of studying linguistic avoidance strategies can be considered as how to better maintain the enthusiasm of second language learners in language communication.

Hayes and Gifford argued that experiential avoidance can be explained by two verbal processes [4]. Language could be seen as an expression of human thought and behaviour. This reflects that avoidance behaviour is closely related to language.

In research from Kleinmann, in the process of learning and using a second language, both language variables and psychological variables will affect learner's behavior [5]. Indeed, when facing unfamiliar language difficulties, learners tend to develop avoidance psychology correspondingly. The author also believes that although the two intersect, psychological factors are the cause of mistakes. However, this research argues that if learners can make themselves proficient in grammar difficulties and use grammar difficulties to express their deep, precise meaning easily, the psychological factor will be less than the linguistic factor, thus avoiding avoidance phenomenon.

Hubert stated that Second language learners commonly use avoidance strategy for communication purposes because they lack the necessary language resources, they seldom use difficult grammatical structures, particularly in writing [6]. This research focuses on learners' issues in writing because grammatical knowledge can highlight difficulties thoroughly in English writing than in oral English. Hubert pointed out specifically the reason why the avoidance principle appeared in English writing. It also provides some basic theoretical support for this research.

In addition, Gallego stated that the difficulty of nonfinite verbs does have a related limitation on reading [7]. Sometimes learners need to analyse in combination with specific situations, and sometimes they need to use language sense to make choices. This research also finds this grammar is difficult. In addition, English is a 
compulsory course for Chinese students, who normally learn non-finite verbs in high school, which is an essential knowledge point. Therefore, the research question is designated as this grammar point, and the research object is set as Chinese high school students. This not only satisfies the condition that the mother tongue is Chinese, but also can draw a more obvious conclusion about the second language avoidance phenomenon.

Yang believed that studying on the avoidance problem and working out the solutions has a great practical significance, and the reasons for the phenomenon are related to learning strategies and language acquisition patterns [8]. Therefore, this study on high school students can provide new ideas for teachers to improve their teaching methods.

To sum up, around the phenomenon of avoidance and non-finite verbs, combined with the set research question, the following questions can be used to collect first-hand data through questionnaires. For instance, Chinese high school students' understanding of nonfinite verbs, the frequency of use in English writing, and their understanding of avoidance; English teachers in senior high schools in China have encountered mistakes in students using this grammar point and practical problems in teaching.

Through reading literature, although the research on avoidance and non-finite verbs in second language has reached a certain level, the studies on the reasons for the avoidance phenomenon in the second language acquisition of Chinese high school students are still rare.

The purpose of this research is not only to explore the influence of the avoidance phenomenon, but also to provide some practical help for learning a second language and teaching mode of grammar difficulties in high school English education. Based on the above literature theories, this research will conclude the most relevant reasons for learners' avoidance behaviours of non-finite verbs through questionnaires and writing samples of high school students in actual exams. Recommendations will also be listed pointedly to solve the problems and fill in the research gap.

\section{METHODS}

We used a questionnaire to collect the data. To grasp this phenomenon more comprehensively, we made two questionnaires respectively for senior high school students and their English teachers.

For students, we set up a total of nine questions about the mastery of non-finite verbs, the frequency, the purpose, the awareness of avoiding phenomena and the way to replace non-finite verbs. By now 114 questionnaires were collected. Of those who filled out the questionnaire, $73.68 \%$ were women and $26.32 \%$ were men. Most of them are college students (61.4\%), followed by high school students (27.19), and then graduate students $(10.53 \%)$. Less than $1 \%$ of them are other degrees.

For the senior high school teachers, we made a total of 10 questions concerning the teaching concept, the habits of their students when using non-finite verbs and teaching methods in writing.

\section{RESULTS}

During the present research, we analyzed all the collected students' English writings, as the database and questionnaires with 9 questions, which were 114 pieces in total, to ensure the reliability of this research.

The research could be divided into 2 stages as follow: Firstly, we helped my friend who teaches English in high school carry on two weekly examinations taken from English Weekly Module 3 and Module 4. After each examination I collected the research subjects' papers and copied the writing part. By analysis, we tried to fulfill the questions about the frequency of non-finite verbs to find whether the avoidance phenomenon exists or not in students' writing tasks. In this database, there are merely one or two times about non-finite verbs using in each writing, even with some mistakes. Whereas as for other language forms such as clause and the emphatic pattern, fewer writing errors can be seen in these sentences.

On the second stage, we did some questionnaires with students and teachers (The questionnaires are provided at the end of the paper). For the students, we try to find how do they think about the non-finite verbs (easy or difficult?) and their opinions of the avoidance. As expected, in Figure 1 almost all students (75\%) considered the non-finite verbs is hard to understand and be practiced into the writing tasks. According to Figure 2, 70\% of students choose to avoid some difficult grammar, to prevent themselves from the lower scores.

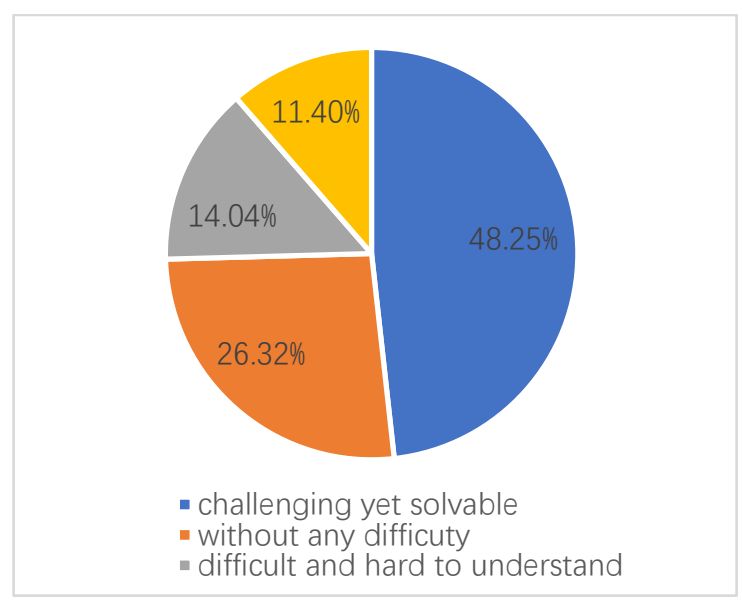

Figure 1. The Difficulty of the Non-finite Verbs 


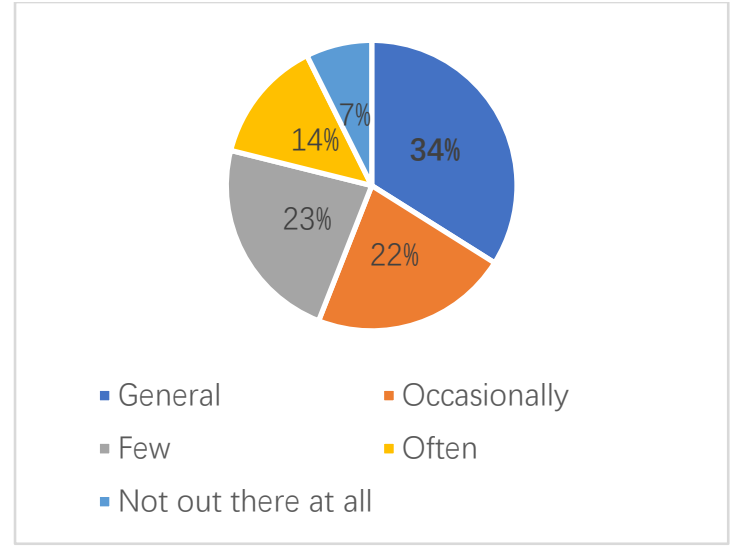

Figure 2. The Avoidance Frequency of Non-finite Verbs Usages

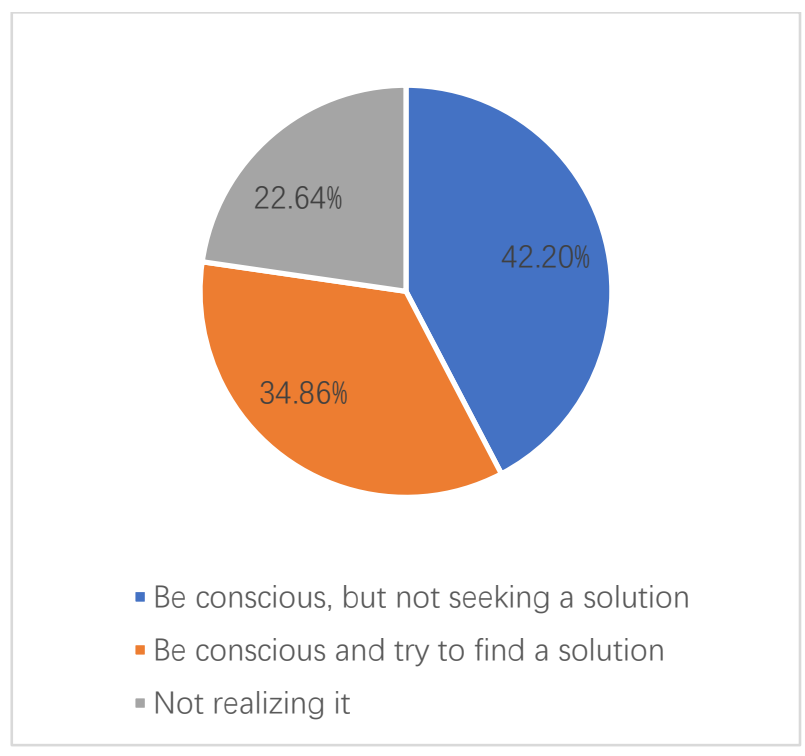

Figure 3. The Percentages of Students' Awareness of their Avoidance Strategy in Writing

In addition, in Figure 3,77\% of learners found that they were aware of the avoidance phenomenon but only $35 \%$ of students tried to seek a solution. That is why we choose this topic, solving these problems for the high senior students. On the other hand, in questionnaires (with 12 pieces) for English teachers in high school, we found that merely $25 \%$ teachers choose " 3 times and more" about the frequency of non-finite verbs in students writing so approximately $90 \%$ teachers often remind their students to use more non-finite verbs and other complex grammar and about 33\% teacher thought that students always avoid non-finite verbs and fail to get high scores because of the monotonous grammar forms.

\section{DISCUSSIONS}

\subsection{Analysis1}

According to the literature search and collation, as well as the collation and analysis of data., we find that many scholars have different studies on avoidance, nonpredicate verbs and even grammar learning of senior high school students. However, little research has been done on this grammatical avoidance problem among Chinese high school students which has a large number. We want to explore the real reasons, so that we can come up with some solutions to help teachers and students overcome this problem accurately, to master English better.

The reasons for senior high school students choose to avoid using that in writing after learning non-finite verbs are various and from different disciplinary perspectives. Among the numerous reasons, the following three reasons are going to be analyzed in detail. From the perspective of senior high school students, we mainly start the narration from two aspects of exam-oriented education system and negative transfer of mother tongue. From the perspective of non-finite verbs, we will analyze the specific areas that are difficult for Chinese senior school students.

At first, China is under an exam-oriented environment. It is widely known that majority of Chinese students are in the exam-oriented education system. This is determined by China's basic national conditions and large population base, which is not going to change in a short period. As senior school students, the thing they should do is to make the mark as high as possible. It is certainly not the only thing because of the development of the education system, but it must be the most important thing in their senior school years. The score is the embodiment of their personal ability, which will be measured and compared everywhere. That is why they need to be restricted by the grading rules, especially in writing which is judged more subjectively. After comparing some exams, such as college entrance examination, CET-4 (College English test 4) and CET-6 (College English test 6), IELTS and TOEFL, we found all of them have very high standards and requirements for students' accuracy in writing. It does not matter how fancy your language is, how complex your sentences are, how rich your vocabulary is, you will get penalized for making a mistake in your writing test. Therefore, students will avoid the non-finite verb consciously or unconsciously to ensure the correct rate.

According to the results of the questionnaire, nearly $95 \%$ of the students will avoid some difficult grammar, including non-predicate verbs in their writing test to ensure the accuracy of the writing grammar. About 50\% of people even choose not to use that or only use them once or twice in writing. However, to make sure that the 
sentences in their essay are fluent, non-finite verb will be replaced by some other sentences or grammar. For example, splitting one sentence into two simple sentences, using conjunctions such as "and, because, but" to form complex sentences, and using clauses (when, if etc.). Among them, majority of people would prefer use compound sentences and clauses to replace.

In addition, according to our survey results, nearly $70 \%$ of the students lost marks for using unfamiliar grammar or words. It is because of such experience that they choose to avoid non-finite verb. Because for them, these examinations are very important to them. However, the number of tests is limited, so trial and error are so costly in writing that they avoid it rather than try and error. For example, the college entrance examination is for entering a satisfactory university, the CET exams are for obtaining a bachelor's degree, IELTS and TOEFL language tests are for meeting the application criteria and getting the opportunity to study abroad. Hence, we will make another questionnaire to have deeper research.

The above is from the perspective of Exam-oriented education environment. Apart from that, for high school students, the influence of mother tongue cannot be ignored.

During the learning process, the negative transfer of mother tongue Chinese is also a cause of avoidance. In China, there is usually only one verb in a sentence. Though there are more than one verb, the form will not change, which makes it confusing for students to compare and acquisition the two languages. For second language learning, people prefer to use structures similar to the mother tongue to express themselves. Grammatical structures such as non-finite verbs, which are not found in Chinese, are more difficult for people to learn, so be avoided using them when expressing consciously or unconsciously.

Psychological problems are the other factors. Due to the big differences between the two languages, and this grammar point is more difficult and error-prone in English, students lack confidence and even resist using it. It will be a vicious circle that if you make a mistake in using non-finite verbs, you will lose marks in the exam, and then the students will be afraid of making mistake, so they will not use that in the next exam. The phenomenon that emerges is avoidance.

\subsection{Analysis2}

The grammar use of non-finite verb is complex in terms of the variable form, the misunderstanding of verb and non-finite verb. The first point that makes non-finite verb difficult to understand lies in the variety of nonfinite verb, basically three forms including infinite form, gerund, and past participle. According to the New English Curriculum Standard for Chinese Primary
School, junior students are merely required to have a command of the use of infinite form especially when they work as an object, object complement and adverbial clause of purpose [9]. To get a good grade in English examination, students spend great effort memorizing the verb phrase in the form of non-finite verb with the help of numerous practices in the form of test. Thus, at the end of the junior school year, most students have a good comprehension of infinite form.

However, students in high school encounter huge difficulty when they first learn to use gerund and participle due to the flexibility of two forms in a sentence. Compared to infinite verb, the use of gerund and particle change with inflection [10]. For example, we can say Clutching a thick book under his arm, he quickly went out. Or we can say, "He quickly went out, a thick book clutched under his arm." The means of these two sentences is comparable but they use different non-finite verb as clutching and clutched. In addition, the inflectional change, non-finite verb plays a flexible role in a sentence. For instance, when present particle works as non-finite verb, it modifies nouns as an attributive, and it serves as an object complement which is changeable with the infinite form, as well as working as predicative and adverbial modifier [11]. Based on the analysis, the form of gerund and particle present in various way with the need of the language environment. Therefore, if students are unable to recognize the form and the grammatical character in the sentence, they slow down their reading speed and face problem of understanding.

The second difficult point lies in the puzzle of predicate and non-predicate. The Collins English Dictionary define predicate as "the part of a sentence in which something is asserted or denied of the subject of a sentence", "one of the two major components of a sentence, the other being the subject". In other words, when students recognize the predicate, they realize that it is an action performed by the subject or the action performer, which is the main clause of a sentence. As for non-predicate, it is another verb in the same sentence which usually exists in the subordinate clause.

Theoretically, while predicate mainly classifies the tense, the use of non-predicate verb differentiates the time order. Based on that, students who confuse the predicate of the main clause may have a divergent understanding of the meaning, leading to lower grade in the test. For instance, the following question requires students to fill in the blank with the proper grammatical form: "Drinking alcohol or using nicotine before bed reduced participants' sleep efficiency, (mean) that the percentage of time they spent in bed actually sleeping was lower." Students may be puzzled by drinking and using as they are in the form of gerund especially working as subject so that students probably have difficulty in recognizing the predicate, which 
therefore is hard to produce the correct answer. In the sentence, the predicate is reduced, indicating that the verb in the blank works as non-predicate.

Meanwhile, the subordinate clause modifies the fact that drinking alcohol or using nicotine before bed reduced participants' sleep efficiency as an attributive, which the gerund form is suitable. In formal style of English and the written English, the gerund form is widely used especially the active form like reading, writing. Sometimes the presence of several verbs in the form of gerund in one sentence increases the complexity for students as well as lowering the speed and the correctness of reading comprehension.

The third important reason is that students have a vague understanding of the logical subject of a sentence when there is non-finite in the subordinate clause. Yang points out that logical subject plays a role in performing or receiving the action in the form of non-finite verb, which means they have logically related with the verbs while they are not the subject directly referred to nonfinite verb [12].

\section{RECOMMENDATIONS}

To solve the problems that teachers encounter in teaching and help learners enhance their second language level better, for the three factors described in the above section, the following are the specific recommendations.

First, as for the negative transfer of mother tongue, the systems are separated in English and Chinese languages. Many sentences that make sense in Chinese will become semantically illogical once they are applied directly to English. Teachers should compare these two systems during the teaching processes and make the learners realize the differences in phonetics, semantics, grammar, structure etc. to minimize the interference of mother tongue system and form a good command of English thinking. Shei stated that the core linguistics of modern Chinese include phonology, vocabulary, grammar structures and pragmatics, concretely reflected in words, units of content, sentences, acts and neologisms [13]. Learners should also consciously understand the cultural background differences between two languages to develop communicative competence in the foreign language. More specifically, cultural differences may be reflected in word order, communicative principles, ways of thinking, family values, aesthetics, moral values, and many other aspects. It is crucial to strengthen the comparison of differences between mother tongue and foreign language cultural background, cultivate students' ability of foreign language communication and reduce mistakes. In teaching, teachers can also compare cultural background differences, such as communication principles, ways of thinking, aesthetic concepts, values, time, and space.
Secondly, China has a large population, and education is the only way out for most majority of people. Therefore, students are under great pressure to learn, which leads to exam-oriented education. Comparatively, Chinese high school students are generally reciting and memorizing English to achieve the goal of scoring in exam-oriented education. However, to really master a language, a learner must combine listening, speaking, reading, and writing to form foreign language thinking. According to Contreras and Pei, language learning needs to be methodical and targeted [14]. Only by learning and using language from its core and essence can second language learners truly communicate with others and express their deep thoughts in this foreign language. As for teachers, improving teaching methods and learners' comprehensive ability are also critical.

Furthermore, non-finite verbs are very difficult. Golombek stated that for both students and teachers, the knowledge gained through practice is richer and more closely related to the results [15]. In practical teaching, teachers should explain abstract grammar points in combination, which is more conducive to learners' memory and understanding. Understanding the meaning of non-finite verbs, being familiar with the different forms of non-finite verbs with practical examples, making linguistic diversity rich are all useful for learners.

\section{CONCLUSION}

To summarize, the research of non-finite verbs avoidance has a practical impact on the English learning of senior high school students in China. It also has a positive influence on teachers' teaching methods.

Based on the above data and analysis, this research identifies three practical factors that are closely related to the research question: negative transfer of mother tongue, exam-oriented education, and grammatical difficulties of non-finite verbs. According to the practical opinions of current senior high school English teachers and students, some practical suggestions are also stated in the above research. As for negative transfer of mother tongue, the different characteristics of the two language systems as well as the differences in cultural background and common sense need to be paid attention to. For exam-oriented education, learners need to take the initiative to form English thinking, and teachers need to upgrade their teaching methods. For the grammatical difficulty of non-finite verbs, learners need to understand, master, and use them, rather than just understand the superficial definition.

In terms of future research, it is hoped that more indepth analysis can be made on avoidance behaviors and phenomena in second language acquisition. With the psychology mentioned above, there is still much to be 
explored about the causes of avoidance. How to enable learners to learn a second language better, rather than just using avoidance strategies to avoid language difficulties, is still a worth exploring problem.

\section{REFERENCES}

[1] Elyildirim, S. (2017). Avoidance strategy in foreign language production. Journal of Süleyman Demirel University Institute of Social Sciences, Number:28, p.231-242. Retrieved from https://sbedergi.sdu.edu.tr/assets/uploads/sites/343

/files/28-sayi-yazi12-1211207

[2] Ahmed, H. (2011). Avoidance in Language Production.

[3] Zhoulin, R. (2000). An analysis of avoidance phenomenon in the second language learning. FOREIGN LANGUAGE EDUCATION.

[4] Hayes, S. C., \& Gifford, E. V. (1997). The Trouble with Language: Experiential Avoidance, Rules, and the Nature of Verbal Events. Psychological Science, $8(3), \quad 170-173 . \quad \mathrm{https} / / /$ doi.org/10.1111/j.14679280.1997.tb00405.x

[5] Kleinmann, H. H. (1977). AVOIDANCE BEHAVIOR IN ADULT SECOND LANGUAGE ACQUISITION1. Language Learning, 27(1), 93$107 . \quad$ https://doi.org/10.1111/j.14671770.1977.tb00294.x

[6] Hubert, M. D. (2011). Foreign language production and avoidance in US university Spanish-language education. International Journal of Applied Linguistics, 21(2), 222-243. https://doi.org/10.1111/j.1473-4192.2010.00276.x

[7] Gallego, N. J. (2010). On the prepositional nature of non-finite verbs. Catalan Journal of Linguistics, 9(1), 79. https://doi.org/10.5565/rev/catj1.95

[8] Yang, G. H. (2011). A study of language avoidance categories in college English compositions and their teaching-learning countermeasures. Journal of Huazhong Agricultural University(Social Sciences Edition).

[9] Education Ministry of the PRC New English Curriculum for Chinese Primary Schools and Junior/Senior Middle Schools(Experimental Version)[M]. Beijing Normal University Publishing Group: Beijing. 2001

[10] Lin, R. (1995). Mother Tongue Interference to Target Language[A]. Journal of Hunan University Social Sciences:Changsha
[11] Gao, S. (1989). Different usage of gerund in English[A]. Journal of Natural Science of Heilongjiang University: Heilongjiang

[12] Yang, J. (2010). On the Difficult Points of Learning Non-finite Verb. [A]. China Electric Power Education: Hebei.

[13] Shei, C. (2014). Understanding the Chinese Language: A Comprehensive Linguistic Introduction (English and Chinese Edition) (1st ed.). Routledge.

[14] Contreras, H., \& Pei, M. (1966). Language for Everybody. What It Is and How to Master It. The Modern Language Journal, 50(5), 301. https://doi.org/10.2307/323239

[15] Golombek, P. R. (1998). A Study of Language Teachers' Personal Practical Knowledge. TESOL Quarterly, $32(3)$,

447. 